\title{
High bandwidth-efficiency solar-blind AlGaN Schottky photodiodes with low dark current
}

\author{
T. Tut ${ }^{\text {a }}$, N. Biyikli ${ }^{\text {b,* }}$, I. Kimukin ${ }^{\text {a }}$, T. Kartaloglu ${ }^{\text {b }}$, O. Aytur ${ }^{\text {b }}$, M.S. Unlu ${ }^{\text {c }}$, E. Ozbay ${ }^{\text {a }}$ \\ ${ }^{a}$ Department of Physics, Bilkent University, Ankara 06800, Turkey \\ ${ }^{\mathrm{b}}$ Department of Electrical and Electronics Engineering, Bilkent University, Ankara 06800, Turkey \\ ${ }^{\mathrm{c}}$ Electrical and Computer Engineering, Boston University, Boston, MA 02215, USA
}

Received 25 March 2004; received in revised form 18 July 2004; accepted 21 July 2004

Available online 5 October 2004

The review of this paper was arranged by Prof. A. Zaslavsky

\begin{abstract}
$\mathrm{Al}_{0.38} \mathrm{Ga}_{0.62} \mathrm{~N} / \mathrm{GaN}$ heterojunction solar-blind Schottky photodetectors with low dark current, high responsivity, and fast pulse response were demonstrated. A five-step microwave compatible fabrication process was utilized to fabricate the devices. The solarblind detectors displayed extremely low dark current values: $30 \mu \mathrm{m}$ diameter devices exhibited leakage current below $3 \mathrm{fA}$ under reverse bias up to $12 \mathrm{~V}$. True solar-blind operation was ensured with a sharp cut-off around $266 \mathrm{~nm}$. Peak responsivity of $147 \mathrm{~mA} / \mathrm{W}$ was measured at $256 \mathrm{~nm}$ under $20 \mathrm{~V}$ reverse bias. A visible rejection more than 4 orders of magnitude was achieved. The thermally-limited detectivity of the devices was calculated as $1.8 \times 10^{13} \mathrm{~cm} \mathrm{~Hz}^{1 / 2} \mathrm{~W}^{-1}$. Temporal pulse response measurements of the solar-blind detectors resulted in fast pulses with high 3-dB bandwidths. The best devices had 53 ps pulse-width and $4.1 \mathrm{GHz}$ bandwidth. A bandwidth-efficiency product of $2.9 \mathrm{GHz}$ was achieved with the AlGaN Schottky photodiodes.
\end{abstract}

(C) 2004 Elsevier Ltd. All rights reserved.

Keywords: AlGaN; Bandwidth-efficiency; Schottky photodiode; Solar-blind

\section{Introduction}

Solar-blind ultraviolet (UV) detectors with cut-off wavelength around $280 \mathrm{~nm}$ can sense very weak UV signals under intense background radiation. These devices have important applications including missile plume detection, chemical/biological agent sensing, flame alarms, covert space-to-space and submarine communications, and ozone-layer monitoring [1-3]. Wide bandgap $\mathrm{Al}_{x} \mathrm{Ga}_{1-x} \mathrm{~N}$ alloy is an intrinsic solar-blind material for $x>0.35$. Since the first demonstration of solar-blind $\mathrm{AlGaN}$ photoconductors [4,5], research on

\footnotetext{
* Corresponding author. Tel.: +90 3122902305; fax: +90 3122664579.

E-mail address: biyikli@ee.bilkent.edu.tr (N. Biyikli).
}

high Al-content $\mathrm{Al}_{x} \mathrm{Ga}_{1-x} \mathrm{~N}$ solar-blind detectors resulted in high-performance devices. AlGaN-based solar-blind photodetectors with very low leakage and noise levels [6,7], high responsivity [8,9], high detectivity $[10,11]$, and fast pulse response [12] have been reported.

AlGaN Schottky photodiodes do not suffer from $\mathrm{p}+$ contact problems. High-quality Schottky and n+ ohmic contacts on $\mathrm{AlGaN}$ layers can be formed using standard processes. In addition, the temporal pulse response of Schottky detectors is not degraded by minority carrier diffusion which makes them suitable for high-speed operation [13-15]. Using these properties, high-performance solar-blind AlGaN Schottky photodiodes were reported by several research groups [16-18]. Recently, we have demonstrated solar-blind AlGaN Schottky photodiodes with low dark current and high detectivity performance [11]. The bandwidth of these detectors was 
below the $\mathrm{GHz}$ level [19]. In this study, we report low dark current solar-blind AlGaN Schottky photodiodes with improved leakage and bandwidth performance. Leakage current of a few fA and bandwidth-efficiency product of $2.9 \mathrm{GHz}$ was achieved with the fabricated solar-blind AlGaN Schottky detectors.

\section{Experimental}

The solar-blind devices were fabricated on MOCVDgrown $\mathrm{Al}_{0.38} \mathrm{Ga}_{0.62} \mathrm{~N} / \mathrm{GaN}$ heterostructures. The detector active region was an unintentionally doped $0.8 \mu \mathrm{m}$ thick $\mathrm{Al}_{0.38} \mathrm{Ga}_{0.62} \mathrm{~N}$ absorption layer. For ohmic contacts, highly doped $n+\mathrm{GaN}$ layer was utilized. The details of the epitaxial structure can be found elsewhere [20]. Fabrication process of the AlGaN Schottky photodiodes was accomplished using a microwave compatible five mask-level standard semiconductor process [20,21]. In sequence, ohmic contact formation, mesa isolation, Schottky contact formation, surface passivation, and interconnect metallization steps were completed. Etching process of $\mathrm{AlGaN} / \mathrm{GaN}$ layers was done using a reactive ion etching (RIE) system. Ti/Al alloy was used as ohmic contact metal. Schottky contacts were formed with thin $(\sim 100 \AA)$ semitransparent Au films.

The fabricated devices were characterized in terms of current-voltage $(I-V)$, spectral responsivity, and temporal pulse response. All measurements were made onwafer at room temperature using a low-noise microwave probe station. $I-V$ measurements were performed with a high-resistance Keithley 6517A electrometer which featured a sub-fA current measurement resolution. However, mainly due to the pick-up noise from the environment and cables, the dark current measurements were limited by the $\sim 2 \mathrm{fA}$ background current floor of the setup. Spectral responsivity measurements were done using a $175 \mathrm{~W}$ xenon light-source, a monochromator, multi-mode UV fiber, lock-in amplifier and a calibrated Si-based optical power-meter. The UV-illuminated solar-blind detectors were biased with a DC voltage source, and the resulting photocurrent was measured using the lock-in amplifier. Temporal highfrequency measurements were done at $267 \mathrm{~nm}$. Ultrafast UV pulses were generated using a laser set-up with two nonlinear crystals. A Coherent Mira 900F model femtosecond mode-locked Ti:sapphire laser was used to generate the pump beam at $800 \mathrm{~nm}$. The pump pulses were produced with $76 \mathrm{MHz}$ repetition rate and $140 \mathrm{fs}$ pulse duration. These pulses were frequency doubled to generate a second harmonic beam at $400 \mathrm{~nm}$ using a $0.5 \mathrm{~mm}$ thick type-I $\beta-\mathrm{BaB}_{2} \mathrm{O}_{4}$ (BBO) crystal. The second harmonic beam and the remaining part of the pump beam were frequency summed to generate a third harmonic output beam at $267 \mathrm{~nm}$ using another type-I BBO crystal with thickness of $0.3 \mathrm{~mm}$. The resulting $267 \mathrm{~nm}$ pulses had $<1$ ps pulse-width and were focused onto the devices using UV-enhanced mirrors and lenses. The detectors were biased using a DC voltage source and a $26 \mathrm{GHz}$ bias-tee. The resulting temporal pulse response was observed with a $20 \mathrm{GHz}$ sampling oscilloscope.

\section{Results and discussion}

Extremely low leakage currents were observed in the fabricated AlGaN Schottky photodiode samples. Fig. 1 shows the measured $I-V$ curve of a small area $(30 \mu \mathrm{m}$ diameter) device. The solar-blind device exhibited leakage current less than $3 \mathrm{fA}$ and $10 \mathrm{fA}$ for reverse bias up to $12 \mathrm{~V}$ and $17 \mathrm{~V}$ respectively. Under $<12 \mathrm{~V}$ reverse bias, the measured dark current fluctuated below the $3 \mathrm{fA}$ level due to the background noise of the setup. Sub-fA leakage currents were observed in this range. Using an exponential fit, we estimate the zero bias dark current less than $0.1 \mathrm{fA}$. The corresponding dark current density for this device at $12 \mathrm{~V}$ was $4.2 \times 10^{-10} \mathrm{~A} / \mathrm{cm}^{2}$. Typical reverse breakdown voltages were measured to be higher than $50 \mathrm{~V}$. In the forward bias regime, turn-on characteristic was observed at $\sim 4 \mathrm{~V}$. Current in this regime increases with a much slower rate than in an ideal photodiode. At $10 \mathrm{~V}$ bias, forward current was only $35 \mathrm{nA}$. We attribute this result to the high series resistance of the devices.

$I-V$ measurements of larger area devices resulted in higher leakage currents. Fig. 2(a) and (b) show the dark $I-V$ curves of $30 \mu \mathrm{m}, 100 \mu \mathrm{m}$, and $200 \mu \mathrm{m}$ diameter devices in linear and logarithmic scale respectively. $200 \mu \mathrm{m}$ device displayed the largest dark current. We measured the reverse bias values where the devices displayed $1 \mathrm{pA}$ leakage current. For 30, 100, and $200 \mu \mathrm{m}$ diameter detectors, $1 \mathrm{pA}$ dark current was reached at $-32 \mathrm{~V},-18 \mathrm{~V}$, and $-12 \mathrm{~V}$ respectively. To make a fair leakage comparison between the devices, the current density values at $5 \mathrm{~V}$ reverse bias were calculated.

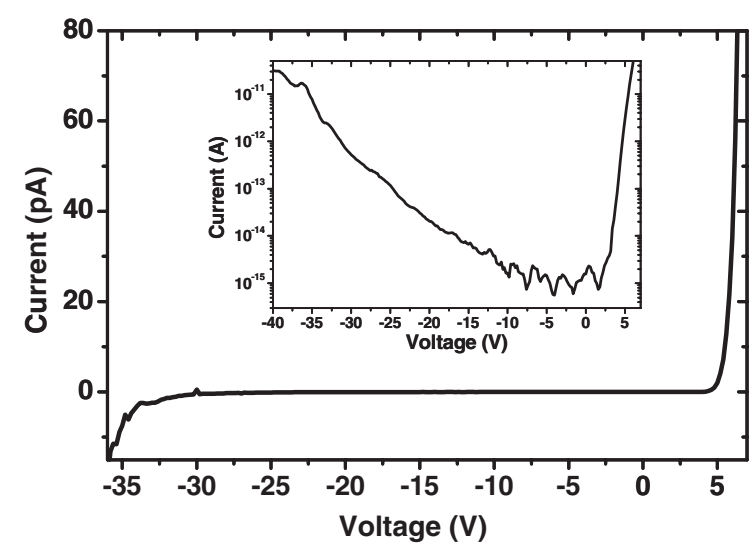

Fig. 1. Dark current of a $30 \mu \mathrm{m}$ diameter solar-blind AlGaN photodiode. The inset shows the same plot in logarithmic scale. 

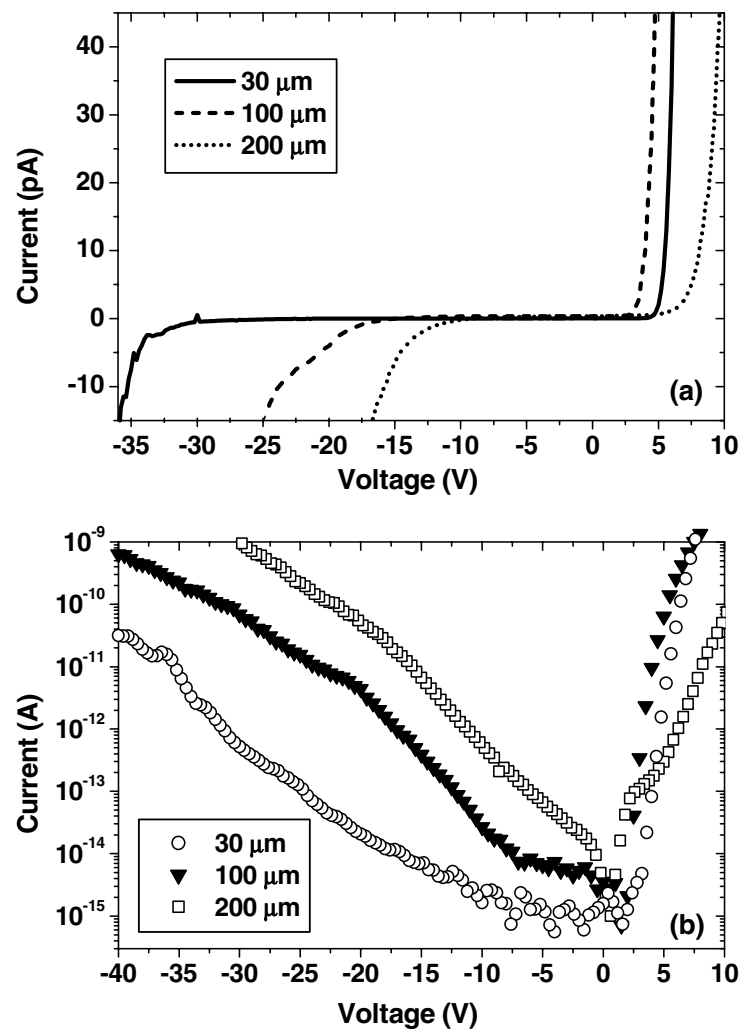

Fig. 2. $I-V$ curves of AlGaN Schottky detectors with different device areas: (a) linear scale, (b) logarithmic scale.

$100 \mu \mathrm{m}$ and $200 \mu \mathrm{m}$ devices exhibited $7 \mathrm{fA}$ and $67 \mathrm{fA}$ dark current at $-5 \mathrm{~V}$, which leaded to $8.9 \times 10^{-11} \mathrm{~A} / \mathrm{cm}^{2}$ and $2.1 \times 10^{-10} \mathrm{~A} / \mathrm{cm}^{2}$ dark current density values respectively. Due to the experimental setup limit, the actual dark current density of $30 \mu \mathrm{m}$ device at $5 \mathrm{~V}$ reverse bias could only be estimated by exponential fitting curve as $3.3 \times 10^{-11} \mathrm{~A} / \mathrm{cm}^{2}$. These results correspond to the lowest leakage performance reported for AlGaN-based Schottky photodiodes. As expected, lower breakdown voltages were observed with increasing detector size. Turn-on voltages of $\sim 2.5 \mathrm{~V}$ and $5 \mathrm{~V}$ were measured for $100 \mu \mathrm{m}$ and $200 \mu \mathrm{m}$ devices respectively.

Spectral photoresponse of solar-blind $\mathrm{AlGaN}$ detectors was measured in the $250-400 \mathrm{~nm}$ spectral range. The bias dependent measured spectral responsivity and quantum efficiency curves are plotted in Fig. 3. Fig. 3(a) shows the strong bias dependence of device responsivity. The peak reponsivity increased from $61 \mathrm{~mA} / \mathrm{W}$ at $250 \mathrm{~nm}$ to $147 \mathrm{~mA} / \mathrm{W}$ at $256 \mathrm{~nm}$ when applied reverse bias was increased from $5 \mathrm{~V}$ to $20 \mathrm{~V}$. The device responsivity saturated for $>20 \mathrm{~V}$ reverse bias, which indicates the total depletion of undoped $\mathrm{Al}_{0.38} \mathrm{Ga}_{0.62} \mathrm{~N}$ absorption layer. A sharp decrease in responsivity was observed at $\sim 265 \mathrm{~nm}$. The cut-off wavelength of the detectors was found as $\sim 267 \mathrm{~nm}$, which ensured the true solar-blind operation of our detectors. Fig. 3(b) shows the semilog plot of the corresponding spectral quantum effi-
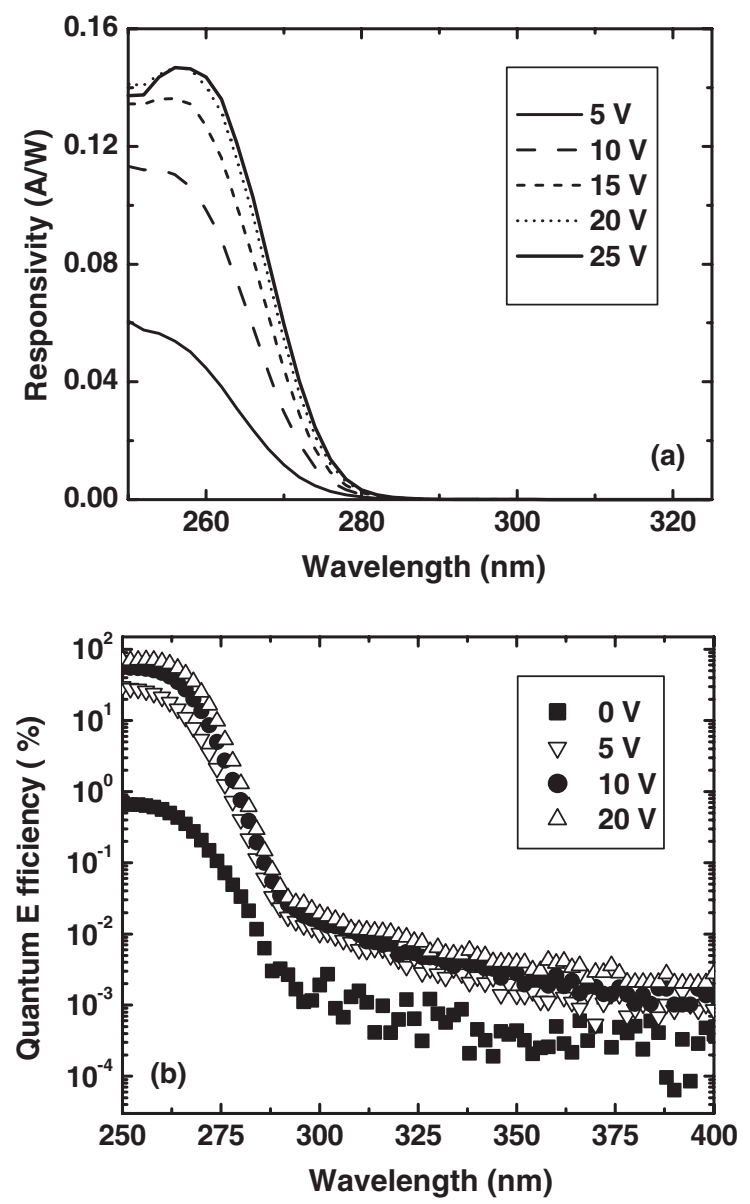

Fig. 3. (a) Measured spectral responsivity curves as a function of reverse bias voltage, (b) corresponding spectral quantum efficiency of Schottky photodiodes.

ciency. The photovoltaic (zero bias) quantum efficiency was very low. When the bias was increased to $5 \mathrm{~V}$, the efficiency was drastically improved by a factor more than 20. The low zero-bias efficiency value and strong bias dependent characteristic of device responsivity indicates photoconductive gain-assisted device operation. The observed photoconductive gain can be explained by the carrier trapping mechanism in $\mathrm{Al}_{0.38} \mathrm{Ga}_{0.62} \mathrm{~N}$ active layer. Pulse response measurements have confirmed our suggestion with carrier trapping limited high-speed results. A maximum efficiency of $71 \%$ at $256 \mathrm{~nm}$ was measured under $20 \mathrm{~V}$ reverse bias. The visible rejection reached a maximum of $\sim 4 \times 10^{4}$ at $10 \mathrm{~V}$ reverse bias.

The detectivity performance of solar-blind detectors is thermally limited since the background radiation within the solar-blind spectrum is very low compared to thermal noise. Therefore, detectivity of solar-blind detectors can be expressed by

$D^{*} \cong R_{\lambda} \sqrt{\frac{R_{0} A}{4 k T}}$ 
where $R_{\lambda}$ is the zero bias reponsivity, $R_{0}$ is the dark impedance (differential resistance) at zero bias, and $A$ is the detector area [22]. Curve fitting method was used to determine the differential resistance of the solar-blind devices [23]. Fig. 4(a) shows the measured and exponentially fitted $I-V$ curves for a $30 \mu \mathrm{m}$ diameter device. A good fit to the experimental data for reverse bias less than $15 \mathrm{~V}$ was achieved. The differential resistance was calculated by taking the derivative $(\mathrm{d} V / \mathrm{d} I)$ of the resulting curve, which is shown in Fig. 4(b). The extremely low sub-fA dark currents resulted in very high resistance values. A maximum resistance of $5.44 \times 10^{17} \Omega$ was obtained at $0.6 \mathrm{~V}$. Zero-bias differential resistance, $R_{0}$ was slightly lower: $4.01 \times 10^{17} \Omega$. These resistance values are $\sim 2$ orders higher than previously reported solar-blind $\mathrm{AlGaN}$ detectors. Combining with $R_{\lambda}=1.4 \mathrm{~mA} / \mathrm{W}, A=7.07 \times$ $10^{-6} \mathrm{~cm}^{2}$, and $T=293 \mathrm{~K}$, we achieved a detectivity performance of $D^{*}=1.83 \times 10^{13} \mathrm{~cm} \mathrm{~Hz}^{1 / 2} \mathrm{~W}^{-1}$ at $250 \mathrm{~nm}$. The detectivity was mainly limited by the low photovoltaic (zero bias) responsivity of the device.

Time-domain pulse response measurements at $267 \mathrm{~nm}$ of the fabricated solar-blind Schottky photodiodes resulted in fast pulse responses with high $3-\mathrm{dB}$ bandwidths. Bias and device area dependence of high-speed performance was analyzed. The corresponding frequency response of the temporal response was calcu-
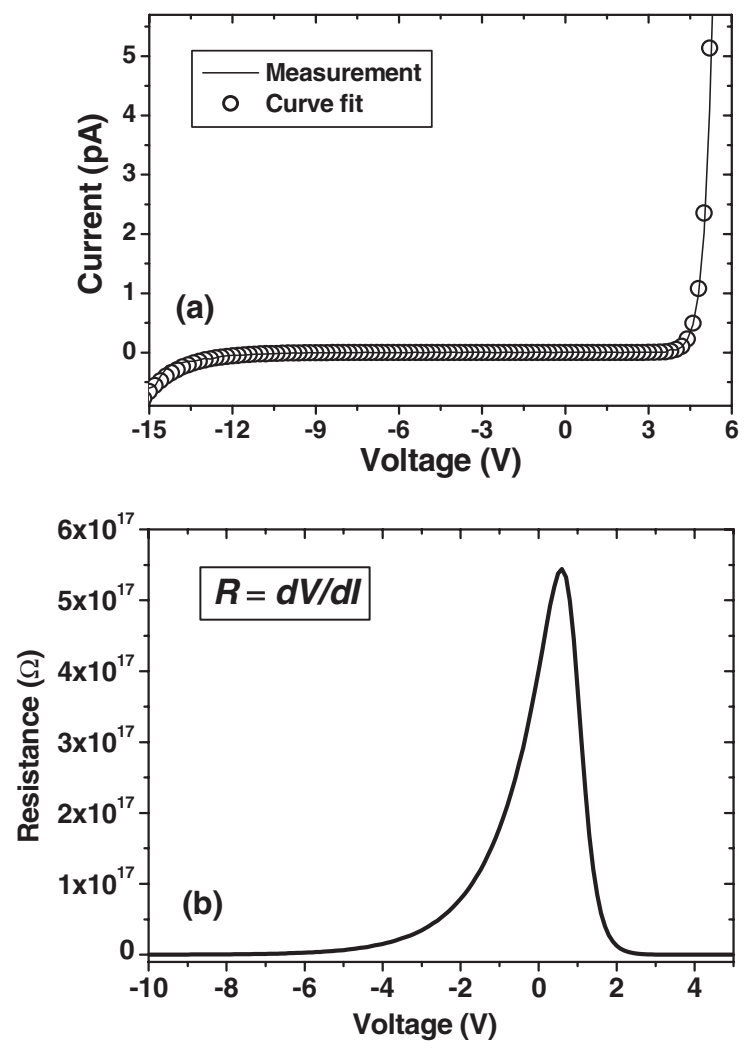

Fig. 4. (a) Linear plot of $I-V$ data and exponential fit for a $30 \mu \mathrm{m}$ diameter AlGaN detector, (b) calculated differential resistance for the same device. lated using fast Fourier transform (FFT). The detector pulse response was bias dependent. Fig. 5(a) shows the pulse response of a $30 \mu \mathrm{m}$ diameter Schottky photodiode as a function of applied reverse bias. Faster pulses with higher pulse amplitudes were obtained with increasing reverse bias as the $\mathrm{n}-\mathrm{AlGaN}$ absorption layer was fully depleted under high reverse bias voltages. The pulsewidth decreased from $80 \mathrm{ps}$ to $53 \mathrm{ps}$ as bias was changed from $5 \mathrm{~V}$ to $25 \mathrm{~V}$. The drop in full-width-at-half-maximum (FWHM) was mainly caused by the decrease in fall time. Short rise times of $\sim 26$ ps were measured. Rise time did not change significantly with bias since it was close to the measurement limit of the $20 \mathrm{GHz}$ scope. The corresponding FFT curves are plotted in Fig. 5(b). As expected, 3-dB bandwidth values increased with reverse bias. A maximum 3-dB bandwidth of $4.1 \mathrm{GHz}$ was achieved at $25 \mathrm{~V}$. Table 1 summarizes the bias dependent high-speed measurement results. Fig. 6(a) shows the normalized pulse responses displayed by detectors with different device areas. All measurements were taken under $25 \mathrm{~V}$ reverse bias. Larger device area resulted in slower pulse response, which can be explained by the increased RC time constant. The corresponding frequency response curves are shown in Fig.
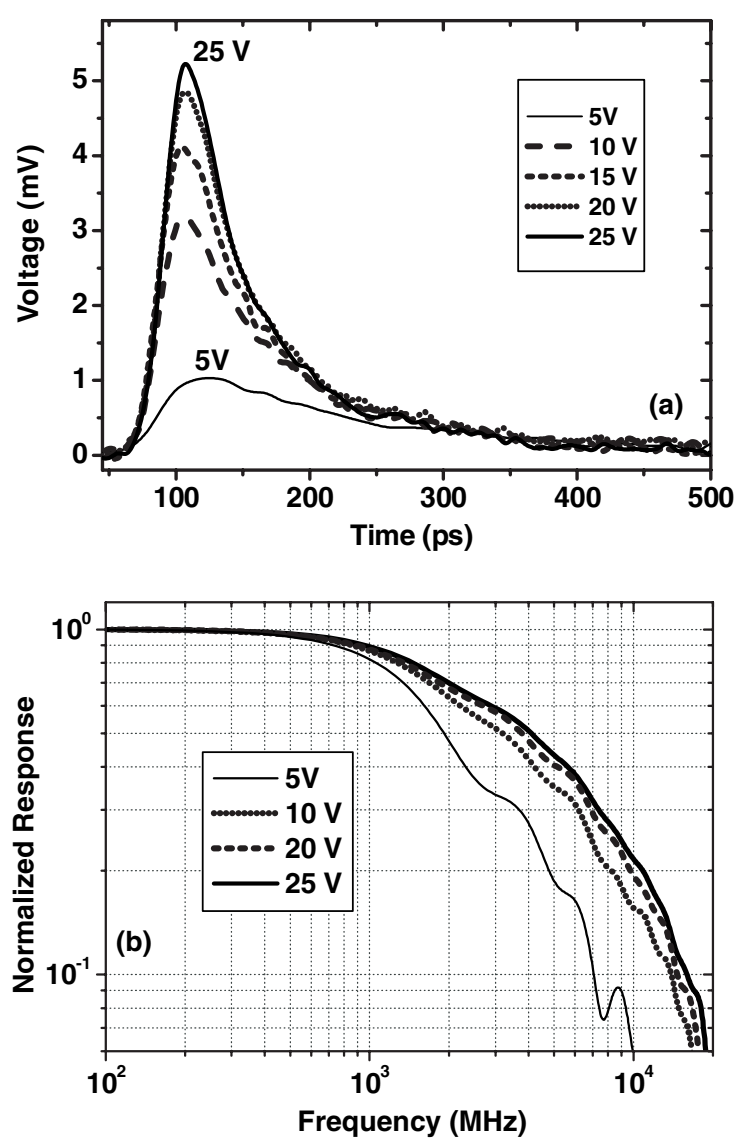

Fig. 5. (a) High-speed pulse response of a $30 \mu \mathrm{m}$ diameter device as a function of applied reverse bias, (b) corresponding FFT curves of the temporal data. 
Table 1

Bias dependent high-speed characteristics of AlGaN Schottky photodiodes

\begin{tabular}{lllll}
\hline $\begin{array}{l}\text { Bias } \\
(\mathrm{V})\end{array}$ & $\begin{array}{l}\text { Rise time } \\
(\mathrm{ps})\end{array}$ & $\begin{array}{l}\text { Fall time } \\
(\mathrm{ps})\end{array}$ & $\begin{array}{l}\text { FWHM } \\
(\mathrm{ps})\end{array}$ & $\begin{array}{l}\text { Bandwidth } \\
(\mathrm{GHz})\end{array}$ \\
\hline 5 & 39 & 161 & 80 & 1.9 \\
10 & 25 & 162 & 71 & 3.2 \\
20 & 28 & 136 & 56 & 3.8 \\
25 & 26 & 117 & 53 & 4.1 \\
\hline
\end{tabular}
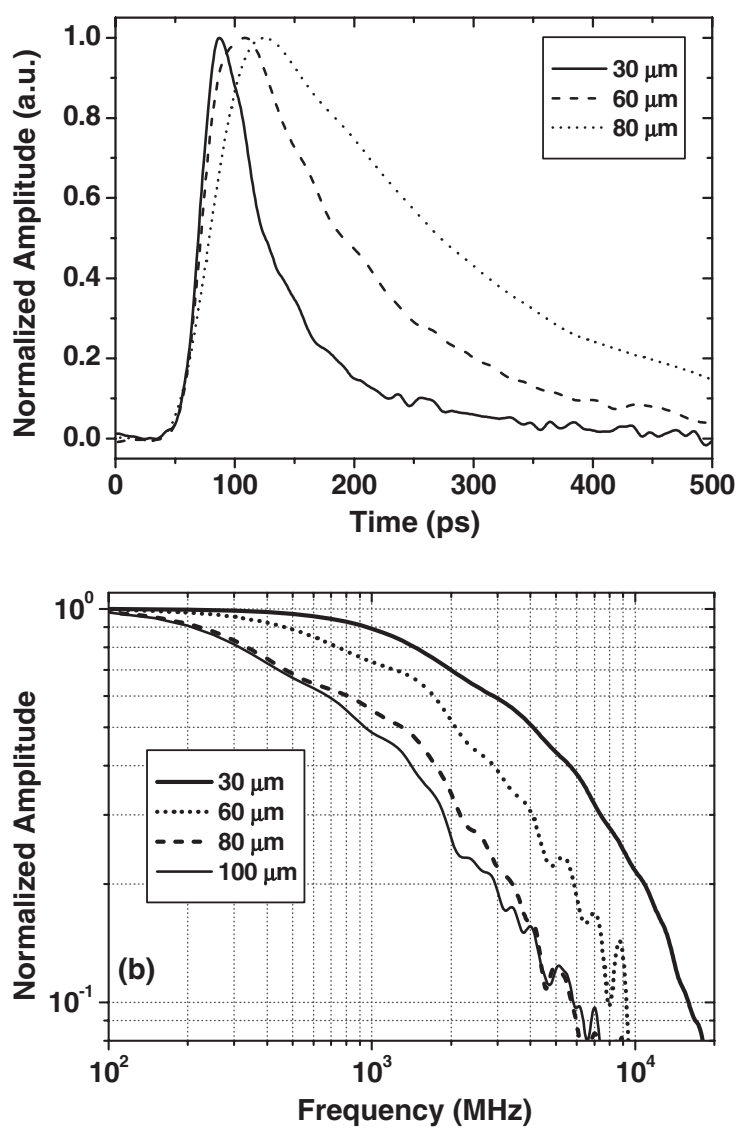

Fig. 6. (a) Normalized pulse response data for detectors with different areas, (b) corresponding frequency response.

6(b). 3-dB bandwidth dropped to $0.95 \mathrm{GHz}$ for $100 \mu \mathrm{m}$ diameter device. The device area dependent high-speed measurement results are given in Table 2.

Mainly three speed limitations exist for photodiodes fabricated on defect-free materials: transit time across the depletion region, RC time constant, and diffusion

Table 2

Device area dependent high-speed characteristics of AlGaN Schottky photodiodes

\begin{tabular}{lllcl}
\hline $\begin{array}{l}\text { Diameter } \\
(\mu \mathrm{m})\end{array}$ & $\begin{array}{l}\text { Rise time } \\
(\mathrm{ps})\end{array}$ & $\begin{array}{l}\text { Fall time } \\
(\mathrm{ps})\end{array}$ & $\begin{array}{l}\text { FWHM } \\
(\mathrm{ps})\end{array}$ & $\begin{array}{l}\text { Bandwidth } \\
(\mathrm{GHz})\end{array}$ \\
\hline 30 & 26 & 117 & 53 & 4.1 \\
60 & 32 & 236 & 117 & 2.1 \\
80 & 53 & 396 & 174 & 1.3 \\
\hline
\end{tabular}

of photogenerated carriers in low-field regions. The fabricated AlGaN Schottky detectors do not suffer from carrier diffusion. Moreover, the carrier transit times in $\mathrm{AlGaN}$ are much shorter than the measured response times due to the high carrier drift velocity [24-26]. The only limitation comes from RC time constant. This makes sense since the series resistance of these devices was high. If RC time constant was the only limitation for our devices, we should be able to fit the fall time components with a simple exponential decay function. However, a reasonable exponential fit with a single time constant could not be achieved. Instead, responses were fitted well with second order exponential decay functions, i.e. with a sum of two exponential decay functions with two different time constants. This shows that another limitation factor exists in our devices. We believe that the additional and slower decay tail was originated by the carrier trapping effect [12]. Photogenerated carriers can be trapped at the defects/trapping-sites in the Al$\mathrm{GaN}$ active layer, which are formed during the crystal growth process. The slower portion of the decay tail is possibly formed by the late arrival of the released carriers which were trapped in these sites. Fig. 7 shows the curve fittings of decay parts for $30 \mu \mathrm{m}$ and $60 \mu \mathrm{m}$ diameter detectors.
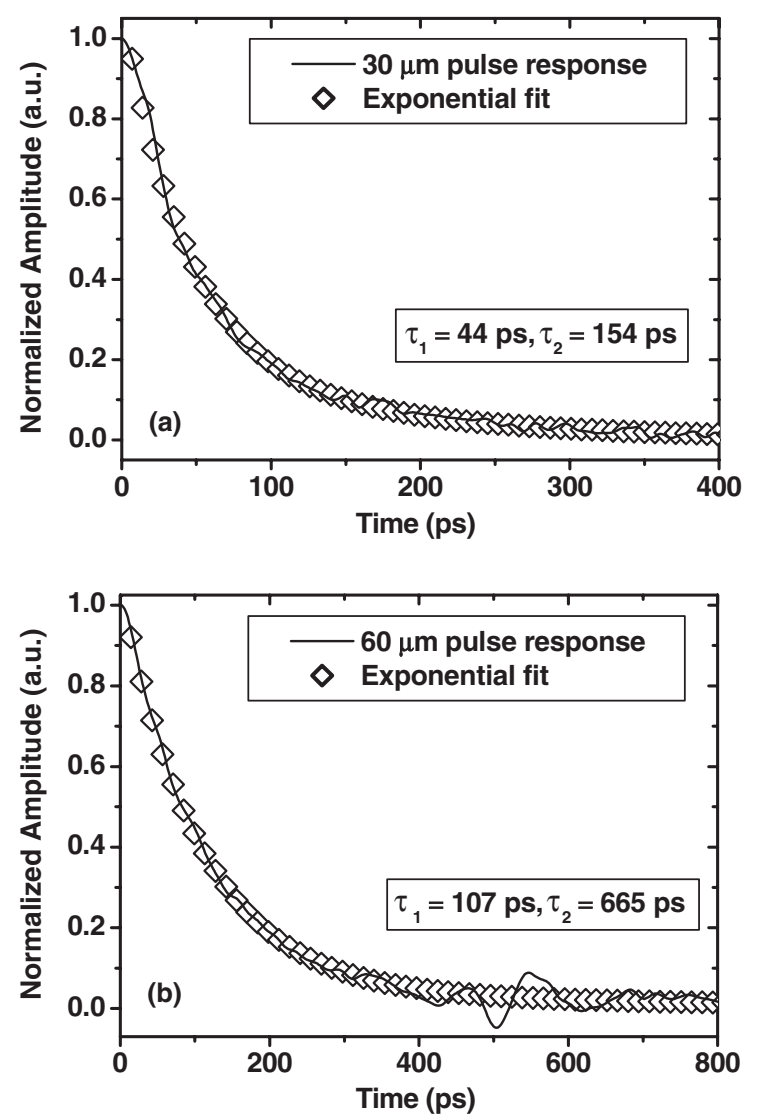

Fig. 7. Second-order exponential fitting to the decay part of pulse response obtained with (a) $30 \mu \mathrm{m}$ diameter device, (b) $60 \mu \mathrm{m}$ diameter device. 


\section{Conclusion}

In summary, high-performance solar-blind AlGaN Schottky photodiodes with low dark current, high responsivity, high detectivity, and high bandwidth were fabricated and tested. Setup limited 3fA dark current at $12 \mathrm{~V}$ reverse bias was measured. Sub-fA leakage and $3.3 \times 10^{-11} \mathrm{~A} / \mathrm{cm}^{2}$ dark current density was estimated at $-5 \mathrm{~V}$. A maximum responsivity of $147 \mathrm{~mA} / \mathrm{W}$ at $256 \mathrm{~nm}$ was measured at $20 \mathrm{~V}$ reverse bias. Sub-fA dark current values resulted in record high differential resistance of $R_{0}=4.01 \times 10^{17} \Omega$. The solar-blind detectivity was calculated as $D^{*}=1.8 \times 10^{13} \mathrm{~cm} \mathrm{~Hz}^{1 / 2} \mathrm{~W}^{-1}$ at $250 \mathrm{~nm}$. Pulse response measurements resulted in $\mathrm{GHz}$ bandwidths. Combining the $3-\mathrm{dB}$ bandwidth of $4.1 \mathrm{GHz}$ with $71 \%$ quantum efficiency, a bandwidth-efficiency performance of $\sim 2.9 \mathrm{GHz}$ was achieved. This value corresponds to the highest bandwidth-efficiency performance reported for $\mathrm{AlGaN}$-based solar-blind photodetectors.

\section{Acknowledgment}

This work was supported by NATO Grant No. SfP971970, Turkish Department of Defense Grant No. KOBRA-002, and FUSAM-03.

\section{References}

[1] Razeghi M, Rogalski A. J Appl Phys 1996;79:7433.

[2] Morkoc H, Carlo AD, Cingolani R. Solid State Electron 2002;46: 157.

[3] Monroy E. In: Manasreh MO, editor. III-V nitride semiconductors applications and devices, 1st ed, vol. 16. Taylor \& Francis: New York; 2003. p. 525.
[4] Walker D, Zhang X, Kung P, Saxler A, Javapour S, Xu J, et al. Appl Phys Lett 1996;68:2100.

[5] Lim BW, Chen QC, Yang JY, Asif Khan M. Appl Phys Lett 1996;68:3761.

[6] Collins CJ, Chowdhury U, Wong MM, Yang B, Beck AL, Dupuis RD, et al. Appl Phys Lett 2002;80:3754.

[7] Li T, Lambert DJH, Beck AL, Collins CJ, Yang B, Wong MM, et al. Electron Lett 2000;36:1581.

[8] Collins CJ, Chowdhury U, Wong MM, Yang B, Beck AL, Dupuis RD, et al. Electron Lett 2002;38:824.

[9] Wong MM, Chowdhury U, Collins CJ, Yang B, Denyszyn JC, Kim KS, et al. Phys Stat Sol (A) 2001;188:333

[10] Kuryatkov VV, Temkin H, Campbell JC, Dupuis RD. Appl Phys Lett 2001;78:3340.

[11] Biyikli N, Aytur O, Kimukin I, Tut T, Ozbay E. Appl Phys Lett 2002;81:3272.

[12] Li T, Lambert DJH, Wong MM, Collins CJ, Yang B, Beck AL, et al. IEEE J Quant Electron 2001;37:538.

[13] Wang SY, Bloom DM. Electron Lett 1983;19:554

[14] Özbay E, Li KD, Bloom DM. IEEE Photon Technol Lett 1991;3:570

[15] Ozbay E, Islam MS, Onat BM, Gokkavas M, Aytur O, Tuttle G, et al. IEEE Photon Technol Lett 1997;9:672.

[16] Osinsky A, Gangopadhyay S, Lim BW, Anwar MZ, Khan MA, Kuksenkov DV, et al. Appl Phys Lett 1998;72:742.

[17] Monroy E, Calle F, Pau JL, Sanchez FJ, Munoz E, Omnes F, et al. J Appl Phys 2000;88:2081.

[18] Rumyantsev SL, Pala N, Shur MS, Gaska R, Levinshtein ME, Adivarahan V, et al. Appl Phys Lett 2001;79:866.

[19] Biyikli N, Kimukin I, Kartaloglu T, Aytur O, Ozbay E. Appl Phys Lett 2003;82:2344.

[20] Biyikli N, Kartaloglu T, Aytur O, Kimukin I, Ozbay E. MRS Internet J Nitride Semicond Res 2003;8:2

[21] Biyikli N, Kartaloglu T, Aytur O, Kimukin I, Ozbay E. Appl Phys Lett 2001;79:2838.

[22] Donati S. Prentice Hall, Upper Saddle River, NJ, 2000.

[23] Collins CJ, Li T, Lambert DJH, Wong MM, Dupuis RD, Campbell JC. Appl Phys Lett 2000;77:2810.

[24] Gelmont B, Kim KH, Shur M. J Appl Phys 1993;74:1818.

[25] Kolnik J, Oguzman IH, Brennan KF, Wang R, Ruden PP, Wang Y. J Appl Phys 1995;78:1033.

[26] Oguzman IH, Kolník J, Brennan KF, Wang R, Fang T, Ruden PP. J Appl Phys 1996;80:4429. 